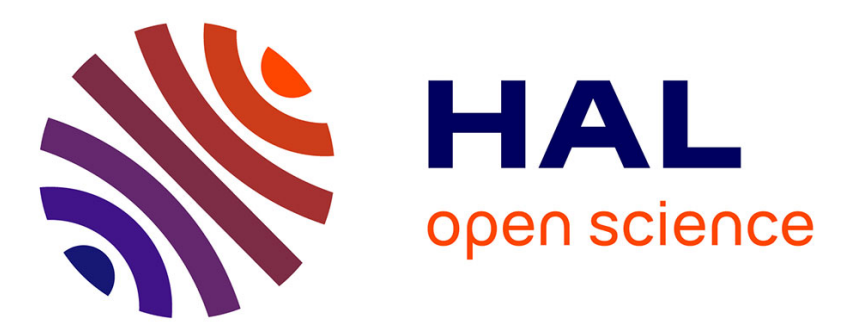

\title{
Application of Hierarchical and Distributed Cognitive Architecture Management for the Smart Grid
} Jacques Palicot, Christophe Moy, Benoît Résimont, Rémi Bonnefoi

\section{To cite this version:}

Jacques Palicot, Christophe Moy, Benoît Résimont, Rémi Bonnefoi. Application of Hierarchical and Distributed Cognitive Architecture Management for the Smart Grid. Ad Hoc Networks, 2016, 41, pp.86-98. 10.1016/j.adhoc.2015.12.002 . hal-01266201

\section{HAL Id: hal-01266201 \\ https://hal-centralesupelec.archives-ouvertes.fr/hal-01266201}

Submitted on 11 Dec 2016

HAL is a multi-disciplinary open access archive for the deposit and dissemination of scientific research documents, whether they are published or not. The documents may come from teaching and research institutions in France or abroad, or from public or private research centers.
L'archive ouverte pluridisciplinaire HAL, est destinée au dépôt et à la diffusion de documents scientifiques de niveau recherche, publiés ou non, émanant des établissements d'enseignement et de recherche français ou étrangers, des laboratoires publics ou privés. 


\title{
Application of Hierarchical and Distributed Cognitive Architecture Management for the Smart Grid.
}

\author{
Jacques Palicot ${ }^{*, a}$, Christophe Moy $^{\mathrm{a}}$, Benoit Résimont ${ }^{\mathrm{a}}$, Rémi Bonnefoi ${ }^{\mathrm{a}}$ \\ ${ }^{a}$ CentraleSupélec/IETR, Avenue de la Boulaie, 35576 Cesson Sévigné Cedex, France \\ tél. +33 [0]2 $99844500-$ fax. +33 [0]2 99844599
}

\begin{abstract}
Moving from the current power grid to the Smart Grid (SG) requires decentralizing management. This should be done by distributing intelligence over the entire grid, thereby, the intermittent production of renewable energy, customer consumption and electricity storage in electrical vehicles (EVs) could be managed in real time. In this paper, the Hierarchical and Distributed Cognitive Radio Architecture Management (HDCRAM), initially proposed to manage Cognitive Radio systems, is proposed for the management of the SG. This architecture can both be applied to the whole SG and to any sub-part (distribution network, production network, microgrid). In this paper we focus on the distribution network and the hierarchical position of each element is identified. As an example, HDCRAM is used for smart home management and multi-agent based modeling shows benefits of such an architecture. In the simulated scenario, without any management the peak power consumption is $5500 \mathrm{~W}$ and the hierarchical and distributed management allows to reduce it to $900 \mathrm{~W}$. This diminution allows to reduce the pressure on the grid and can decrease the risk of failure.
\end{abstract}

\footnotetext{
${ }^{*}$ Corresponding author

Email address: jacques.palicot@centralesupelec.fr (Jacques Palicot)
} 
Key words: Smart Grid (SG), Smart home management, Hierarchical and Distributed Cognitive Radio Architecture Management (HDCRAM), multi-agent systems, JADE.

\section{Introduction}

The European Technology Platform (ETP) Smart Grids was set up in 2005 to create a joint vision of European networks for 2020 and onwards [1]. According to the European Commission, the definition of the Smart Grid is a follows [2].

Definition 1. A Smart Grid is an electricity network that can cost efficiently integrate the behavior and actions of all users connected to it - generators, consumers and those that do both - in order to ensure economically efficient, sustainable power system with low losses and high levels of quality and security of supply and safety.

A more explicit definition is given by the Energy Independence and Security Act of 2007 [3].

Definition 2. The term "Smart Grid" refers to a modernization of the electricity delivery system so that it monitors, protects, and automatically optimizes the operation of its interconnected elements, from the central and distributed generator through the high-voltage transmission network and the distribution system, to industrial users and building automation systems, to energy storage installations, and to end-use consumers and their thermostats, electric vehicles, appliances, and other household devices. 
This latter definition (def. 2) incorporates the distribution and transmission networks that are major agents in the Smart Grid. Moreover, it includes many different actors that will participate in the Smart Grid such as electric vehicles, thermostats, etc. Six categories of communications have been identified by the Department of Energy (DOE) : Advanced Metering Infrastructure (AMI), Demand Response or Demand Side Management (DR or DSM), Wide Area Situational Awareness (WASA), Distributed Energy Resources and Storage (DERS), Electric Transportation or Electric Vehicles (ET or EV) and Distribution Grid Management (DGM) 4]. Management of such a complex network is of great importance and this is the purpose of this paper. The electrical grid will become a smart system. Introducing smartness is all about increasing communications between local entities in order to coordinate all the elements of the global system.

Indeed, it is mandatory to refer to communications when we talk about the Smart Grid. The data volume exchanged by the different actors is such that it would be impossible to transport the data without a reliable and distributed communication system. Cognitive radio [5] 6] could be an efficient way to transport the data without overloading the frequency spectrum [7]. It has been envisaged to use different frequency bands for cognitive communications for the Smart grid [8], for example, free TV bands [9] [10], in [11], authors consider the use of cognitive communications over unlicensed band for home communications and over licensed band for communications over longer distances. In [12] the smart grid is viewed as a huge Wireless Sensors Network (WSN) in which all the elements of the smart grid communicate using cognitive radio. These papers are applying Cognitive Radio to the Smart Grid from the SG communication point of view. In this paper, 
the application of $\mathrm{CR}$ is done through the application of a Cognitive Radio Manager to the Smart Grid. The Smart Grid management architecture affects the complexity of the management of cognitive radio equipments, as a consequence, the design of the architecture must take into account the communication system.

In order to fulfil the communication requirements of the SG, we propose to use a Cognitive Radio Management Architecture that was initially proposed during the first CROWNCOM conference in 2006 [13]. This architecture, named HDCRAM for Hierarchical and Distributed Cognitive Radio Architecture Management, was successfully demonstrated in several Cognitive Radio (CR) scenarios such as the Dynamic Spectrum Access (DSA) [14] $15]^{1}$.

We believe that the current centralized management of power system, is not suitable anymore for several reasons such as the increasing consumption, the introduction of distributed renewable energy (distributed geographically and in time), the customers involvement, the huge amount of data to handle, etc. We believe that, in the case of the management of such a big and complex system as the SG, the management should be distributed among all actors of this system and HDCRAM could be a management solution. This is what we would like to highlight in this paper.

Some hierarchical and distributed architectures have already been proposed for the Smart Grid. In [16], coordinators receive information from

\footnotetext{
${ }^{1} \mathrm{~A}$ demonstration is also available on the internet : https://youtu.be/0-MIpPwgG4E
} 
consumer or from the lower level coordinators and broadcast to all agent the same data which are used to make decisions. In [17, the architecture has three levels and decision can be done at the microgid level, at the feeder level or at the substation level. In these articles hierarchical architectures are only used for demand-side management and for management pricing. In [18], a detailed hierarchical and distributed architecture is proposed for microgrid management but this architecture hasn't been applied over a larger part of the grid as we do in this paper.

In summary, in this paper :

- A hierarchical architecture (coming from Cognitive Radio domain) is proposed for the distribution network and is used to manage consumption, intermittent production, storage and grid monitoring;

- The hierarchical position of each element of the grid (e.g. Smart Meters, Phasor Measurement Units (PMUs) or EV aggregator) is clearly identified in this paper.

- This architecture is finally implemented for Smart Home management

This architecture can also be mapped on any of the sub parts of the SG. Moreover, HDCRAM is composed by two independent paths, one for the cognitive management and the other for the (re)configuration management, that differentiates it from existing solutions.

This paper is organized as follows: Section 2 describes the basics of HDCRAM, while Section 3 proposes the deployment of HDCRAM for the 
SG (illustrated by two clear schemes). In this section, the metrics used for both the cognitive information and the reconfiguration orders are also described for some elements of the networks. Section 4 gives a concrete example and its simulation through an agent-oriented implementation using JADE (Java Agent DEvelopment Framework). Conclusions are drawn in Section 5 ,

\section{Hierarchical and Distributed Cognitive Radio Architecture Man- agement (HDCRAM)}

This section presents an architecture designed at first for Cognitive Radio purposes [19]. Its name is Hierarchical and Distributed Cognitive Radio Architecture Management, in short: HDCRAM. The HDCRAM architecture is depicted in Figure 1. The cognitive cycle (see Figure 2) shows that a Cognitive Radio equipment or system has three main activities: a sensing activity, an intelligent activity (decision making) and a reconfiguration activity (adaptation). In HDCRAM, those activities are distinguished. The two other characteristics that are also well separated in HDCRAM, are the management architecture (level 1,2 and 3) and the radio transceiver chain (at operator's level). Hence HDCRAM is all that has to be added to transform a non-intelligent legacy system to a smart system, whatever the system is: radio, grid, city, car, etc.

As it can be seen in Figure 1, this architecture comprises two managing sub-parts [20]:

- A cognitive part featuring Cognitive Radio Management Units (CRMu): a CRMu exchanges information from the lower level to the upper level 


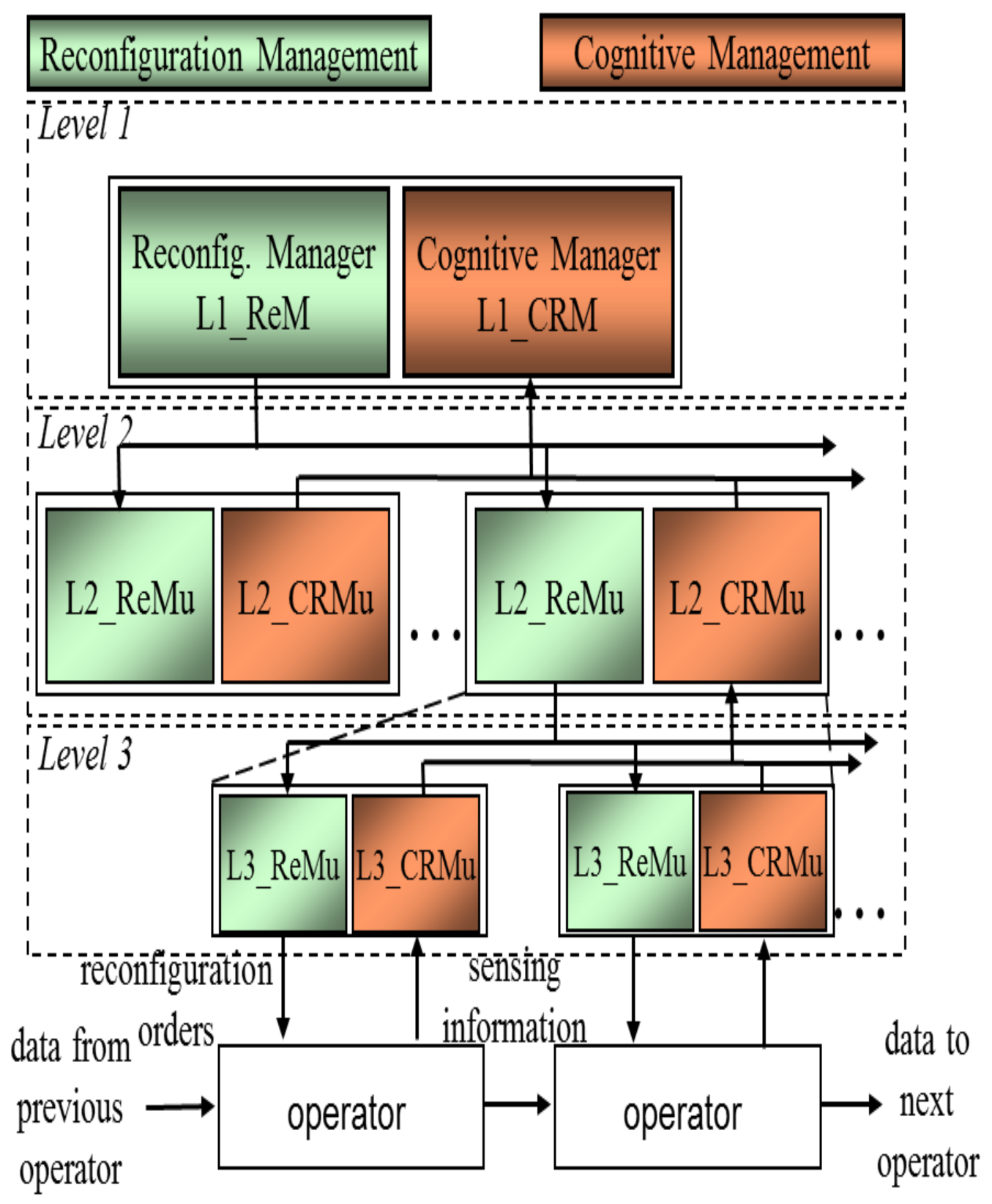

Figure 1: Hierarchical and Distributed Cognitive Radio Architecture Management [20] over a processing chain made of reconfigurable operators. The processing chain targeted by HDCRAM was initially made of radio processing elements and we propose in this paper to target the elements of the grid. 


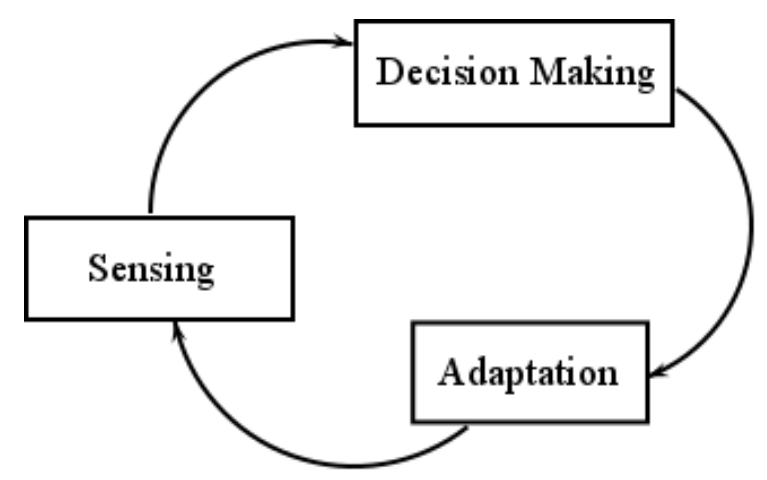

Figure 2: Simplified cognitive cycle

only. This entity has intelligent capabilities, and can make decisions and alert the upper-level CRMu;

- A reconfiguration part featuring Reconfiguration Management Units (ReMu): a ReMu exchanges information from the upper to the lower level only. This entity receives reconfiguration orders from the upper level and transmits them to the lower level ReMu.

Communication can also exist from a CRMu to a ReMu at the same level. Figure 1 shows also a three-levels architecture:

- Level 1 (L1): is composed of the couple L1_CRM/L1_ReM and is the general manager of the system and is unique;

- Level 2 (L2). Level 2 is composed of several couples (L2_CRMu/L2_ReMu). They provide L1 with an abstraction of the lower level L3 by not sending to L1 all the information they receive from L3 but only the necessary information. Then L2 acts as a compression level in order to decrease the amount of data to be handled in the management architecture; 
- Level 3 (L3). Level 3 is composed of several couples (L3_CRMu/L3_ReMu). Each of these couples is associated to an operator. L3 ReMu is the entity that is able to reconfigure its associated operator, and L3_CRMu is used to process the data that come from the operator.

- Operators: an operator is a modifiable component of the managed system (for example a filter or a signal to noise ratio sensor in the radio context).

The intelligence is distributed because the real-time constraints would be difficult to handle if all the decisions were made in a centralized way. This hierarchical and distributed architecture allows to make decisions at different level [20]. A local and simple decision is made at level L3 (little cycle in Figure 3). If the decision is more complex or involves other operators, the decision is made at level L2 (Figure 4 ). Lastly, if many operators are involved, the decision is made at level L1 (Figure 5). For example, Figure 6 zooms on the sub-part of a smart radio transceiver that could change the modulation when the Signal to Noise Ratio is below a given threshold [21]. In this context, when L3_CRMu management unit of SNR sensor detects that the threshold is crossed, L3_CRMu of the SNR sensor can not directly affect the configuration of the mapping operator through its L3_ReMu. As a consequence, L3_CRMu of the SNR sensor has to refer to L2_CRMu of L2_Modulation management that can reache Mapping management L3_ReMu to manage the reconfiguration of the operator (medium decision cycle is used).

In order to help the reader really understand this HDCRAM architecture, Figure 7 provides an example of the OSA (Opportunistic Spectrum 


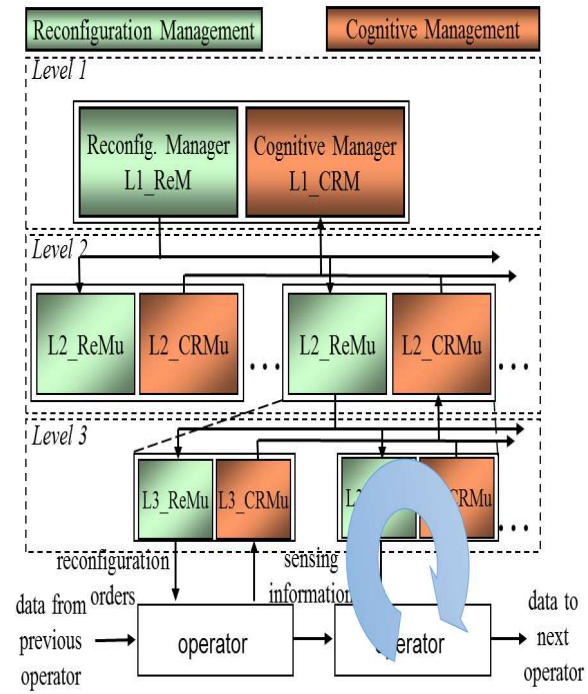

Figure 3: A little cycle (includes one level L3)

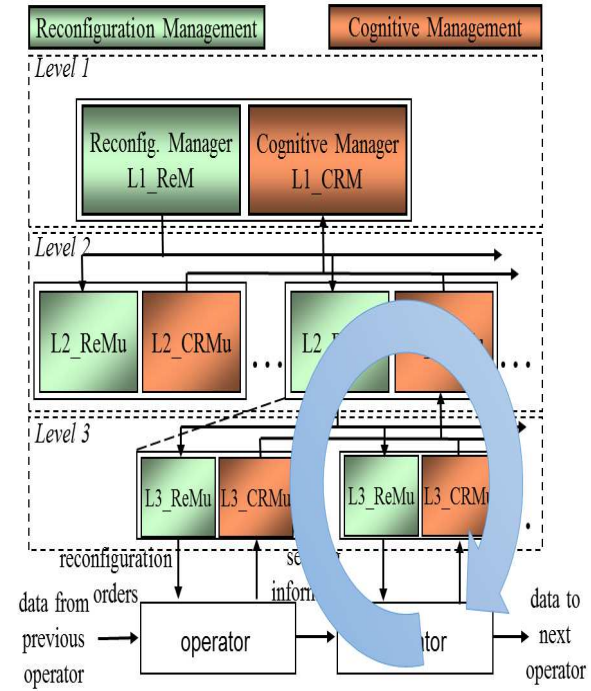

Figure 4: A medium cycle (includes two levels L2 and L3)

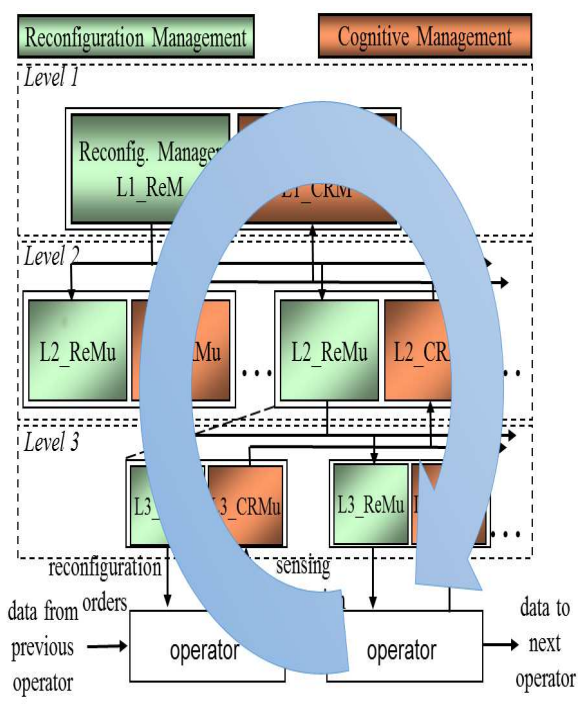

Figure 5: A big cycle (includes all three levels) 


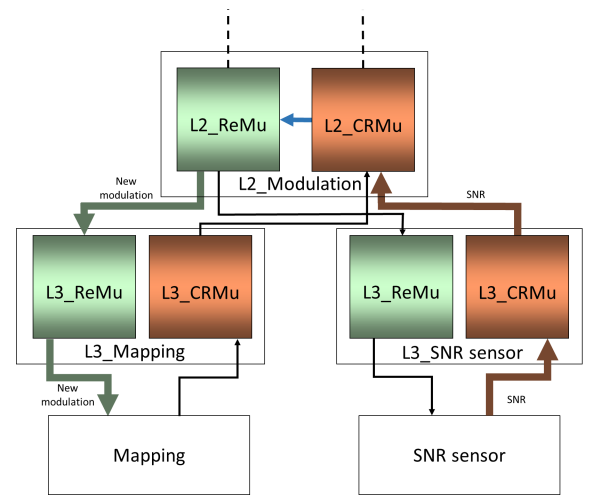

Figure 6: Example of utilization of HDCRAM, the decision to change the modulation is made in the L2_ReMu and only the elements involved in the decision process are illustrated in this scheme

Access) challenge. OSA is a futuristic spectrum access scheme aiming to mitigate radio-frequency spectrum congestion. With OSA, future radio devices will be more agile in frequency and then should be able to change their transmitting frequency dynamically. It consists at giving new rights to so called Secondary Users (SUs) that could use the spectrum let vacant from time to time by licensed users, e.g. Primary Users (PUs). This scenario is only acceptable if SUs never interfere with PUs. A SU runs a spectrum holes sensor that senses its radio environment and sends an information about the presence or absence of a PU communicating in the targeted channel to its corresponding L3_CRMu. If a channel is free, e.g. not used by a PU, there is a hole in the spectrum and a $\mathrm{SU}$ can use it. If a PU uses the channel, the SU cannot use this channel and should seek for other channel opportunities and consequently should reconfigure its radio parameters such as carrier frequency. Here is the detail of the reconfiguration process that occurs inside the cognitive equipment from the sensor to the reconfiguration action. In 
this scenario, The L3_CRMu in charge of the sensor can't make the decision but should send a piece of information to its corresponding L2_CRMu. Finally, this last entity concludes that the channel is no longer available. In this scenario, L1_CRM has been designed to provoke a changing of the carrier frequency in order to explore another radio channel, thus L2 and L3 in charge of spectrum sensing can't make the decision. Consequently, the sensing result of "Spectrum Holes Sensor" is transmitted through L3_CRMu and then L2_CRMu to inform L1_CRM, which then sends a reconfiguration order to L1_ReM. L1_ReM sends a reconfiguration order to the L2_ReMu in charge of channel selection and to the L2_ReMu in charge of Common Pilot Channel (CPC) necessary to coordinate SUs that are communicating together, so that they can exchange their frequency parameters. Finally, the $\mathrm{SU}$ can check if the new band is free.

In order to have a high-level specification of this architecture, HDCRAM was modeled by using the Unified Modeling Language (UML) language. The use of an executable programming language, such as $\mathrm{C}, \mathrm{C}++$, Java, etc., in combination with UML and a metamode ${ }^{2}$ simulates the architectures that are modelled [20].

The HDCRAM has some particularities that make it interesting for Smart Grid management, the main ones are :

- Two totally independent paths for the cognitive management and for the (re)configuration management.

- HDCRAM is a model of an architecture independent of the process-

\footnotetext{
${ }^{2} \mathrm{~A}$ metamodel is used to make the link between a diagram and a code template.
} 


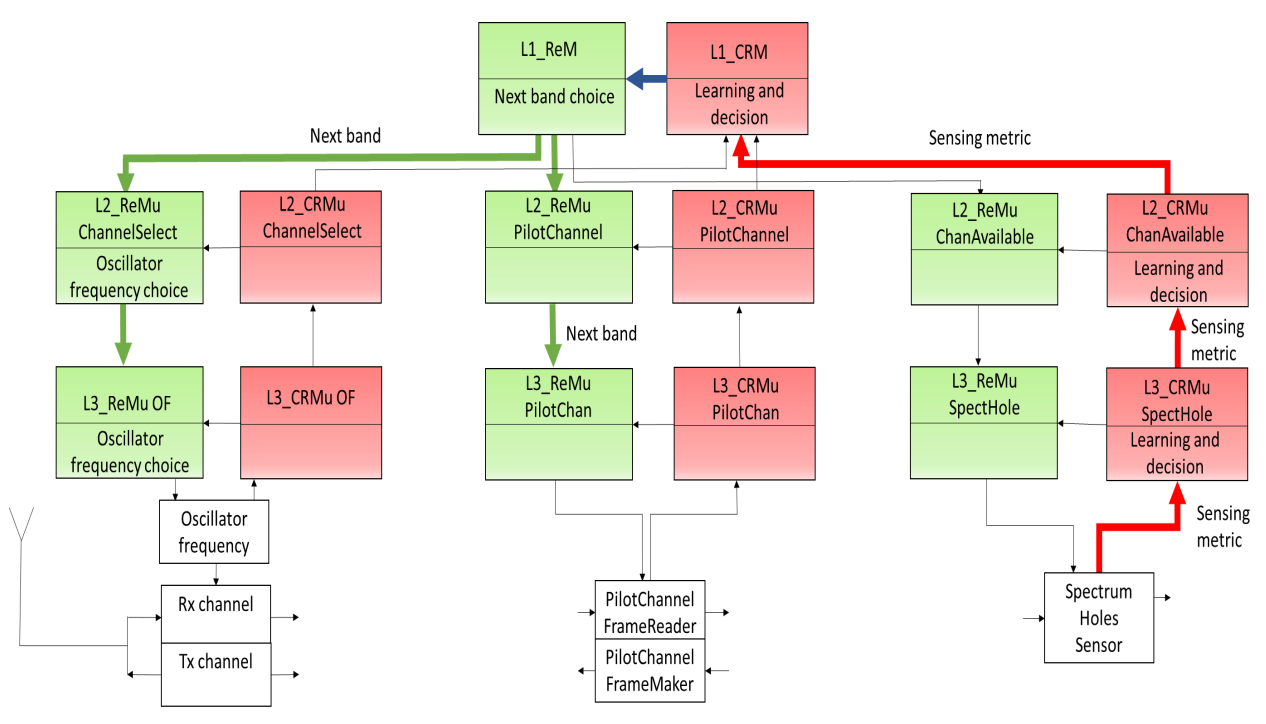

Figure 7: Example of HDCRAM deployment for OSA purpose

ing which are performed in the connected"boxes"."HDCRAM model" provides a skeleton of a management architecture.

- "HDCRAM model" is implemented in a specific "HDCRAM implementation" for a given smart scenario.

- Three levels of possible decisions, which corresponds to three different cognitive cycles in the architecture.

- HDCRAM model could be applied to any complex systems. The rules and the connections between the "boxes" of the architecture help the designer of the smart system to deploy smart scenarios and to specify the different elements necessary to implement this scenario. Therefore it could be applied to the entire SG comprising energy production (monitoring renewable energy,etc.) and not limited to home environment. 
- An "HDCRAM implementation" could be emulated, simulated in order to predict the behavior of a system following a given smart scenario.

- An "HDCRAM implementation" could embed any decision making algorithms.

\section{Application of Hierarchical and Distributed Cognitive Archi- tecture for the Smart Grid}

HDCRAM has been proposed within the framework of Cognitive Radio but it could be applied to any big and complex system with self-adaptation requirements, such as the Smart Grid. In brief, HDCRAM is a management tool used at first to represent a Cognitive Radio system but can be generalized to represent and manage complex and heterogeneous self-adaptive systems. HDCRAM could be an interesting solution to manage efficiently the grid. Hierarchical and distributed architectures already exist for the power system, but it is often related to the transmission part of the grid. With this HDCRAM approach, these hierarchical and distributed architectures can be generalized to the entire grid or to any sub part. The distribution part of the grid is the one whose management needs will increase the most in the coming years, that's why we maps the HDCRAM on this sub part. This gives moreover the opportunity to merge a lot of the Smart Grid aspects into a unique coherent system.

\subsection{Mapping on the distribution network}

Figure 8 and 9 hhows two sides of the same representation, cut for clarity purposes, of HDCRAM deployment for the Smart Grid. For many re- 
searchers and industrial stakeholders of the Smart Grid community, such as [22],improvements must be performed in the distribution network to enable the Smart Grid. Indeed, a lot of topics currently studied are related to the distribution network: demand side management programs that are enabled by distribution companies, the integration of renewable energy and storage facilities. This is, most of the time, located at the distribution level, and dealt with distribution networks monitored by PMUs, etc. This is the reason why the distribution data center is the level one (L1) in Figure 8.

Level two (L2) divides the distribution management into its three main challenges:

- The network monitoring, being represented by phasor data concentrator (fig. 8) (PDC);

- The consumers Participation (DSM vision), being represented by the home smart meter and the industrial smart meter (fig. 8).

- The integration of renewable energy and storage facilities, which is represented by the wind farms' monitoring, the PV farms' monitoring and the EV aggregator (fig. 9p.

It is important to notice that, in those Figures, the energy grid and the management architecture are well separated.

With this proposed architecture, distribution companies are relieved from a part of the management. Indeed, local problems are solved locally thanks to the distributed management. If, for instance, the energy consumption of customers, in a certain area, is too large and there is therefore 


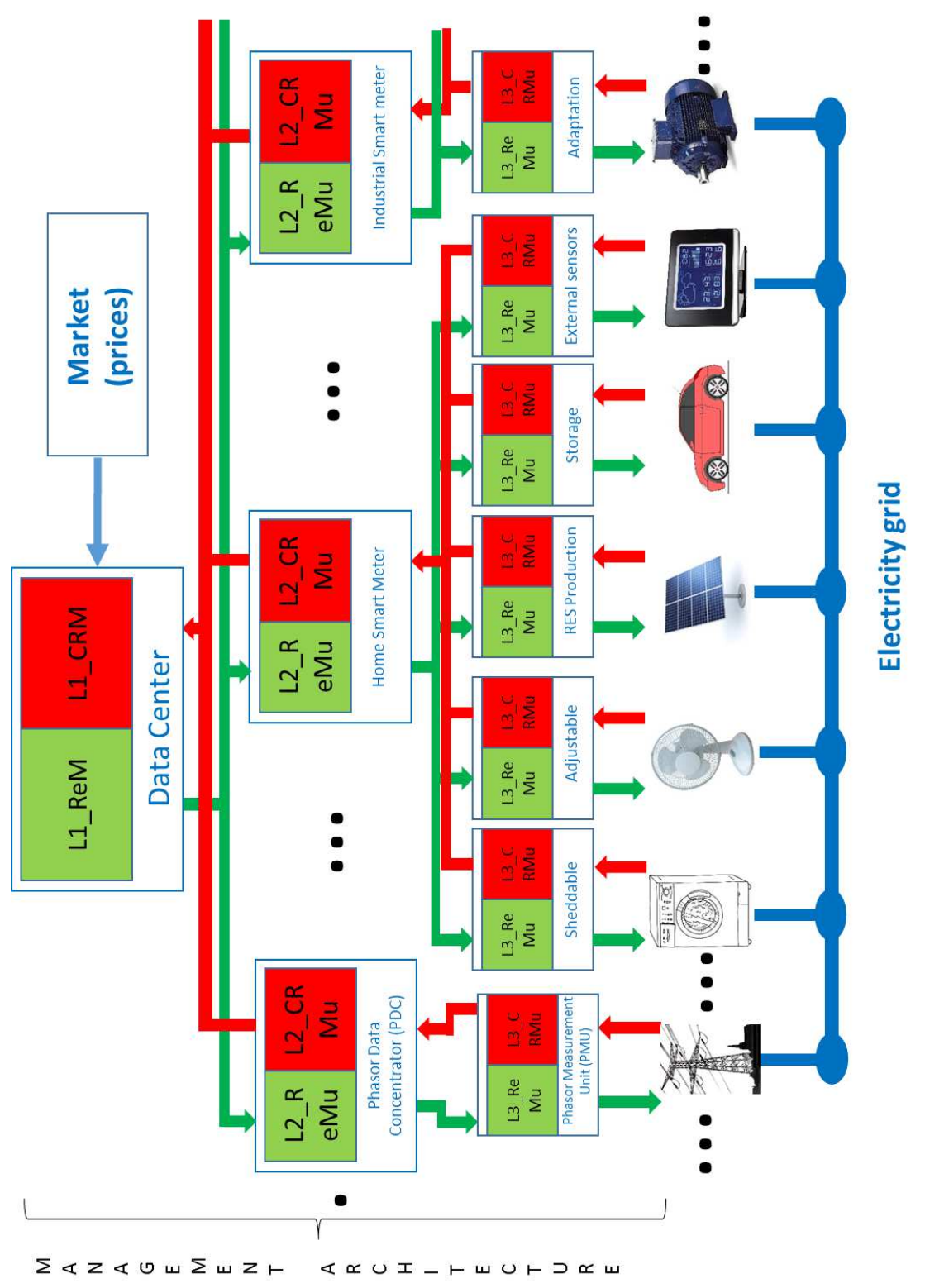

Figure 8: HDCRAM deployment for the Smart Grid (part one) 


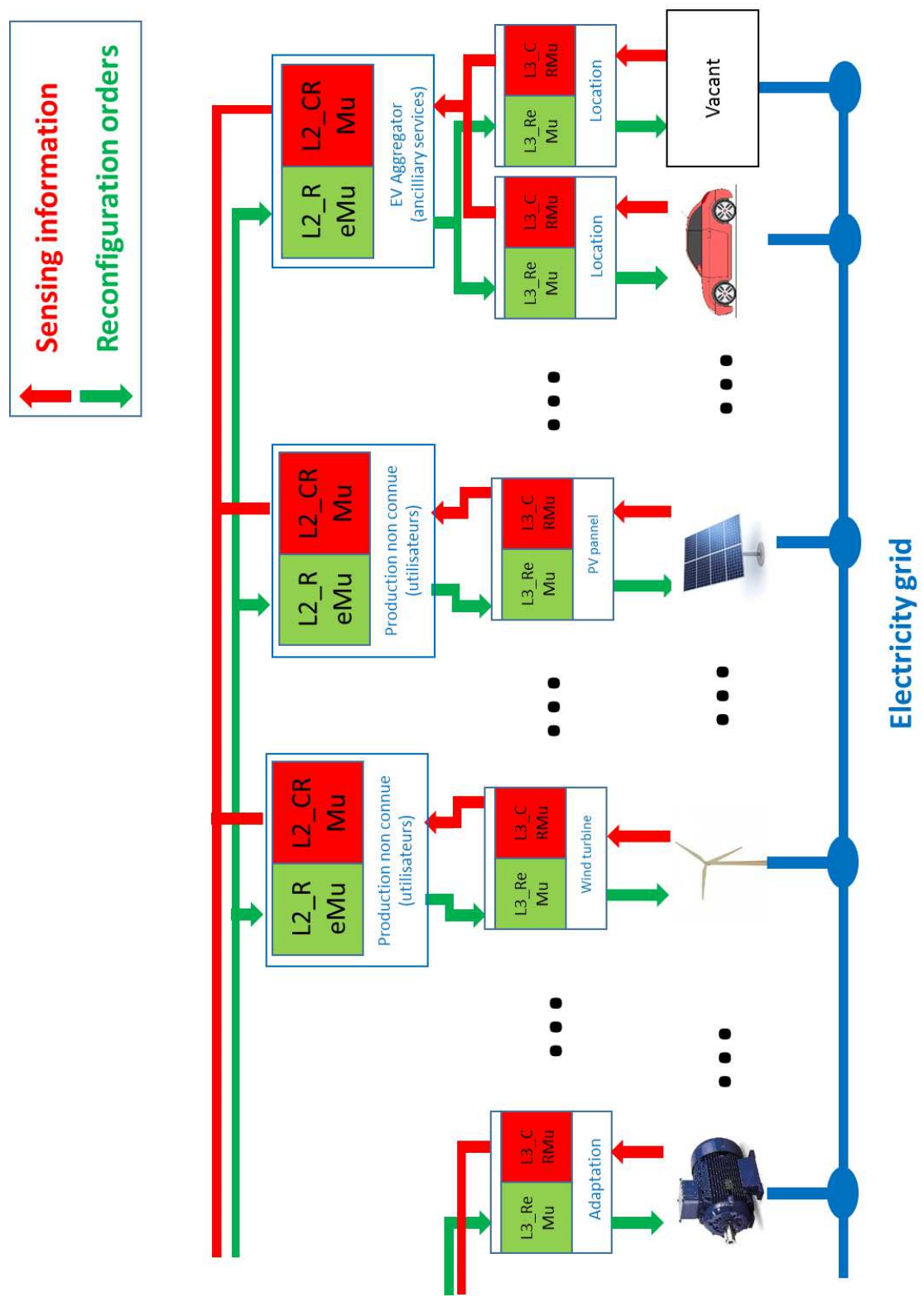

Figure 9: HDCRAM deployment for the Smart Grid (part two) 
a pressure on the grid (information received from a PDC), smart meters will first try to solve the problem by adapting or shifting some loads or propose customers to do so by offering them a lower electricity price (Real Time Pricing program). If the engendered load modification is not sufficient, the PDC still sends information about critical states for some lines, the distribution data center will send reconfiguration orders to EV aggregators and to renewable energy sources in order to increase electricity generation. For instance, if some wind turbines/PV panels are switched off in a wind/PV farm and there is a lot of wind/sunshine, a switching ON order will be sent. EV aggregators would also propose interesting prices in order to encourage people to discharge their car batteries into the grid.

\subsection{Description of level 2}

\subsubsection{Network monitoring (L2 PDC of figure 8)}

A phasor data concentrator (PDC) is used to collect the data that come from all the PMUs [23]. A Level three (L3) related to a PDC is necessary for a PMU to be set up on a line. In runtime operations, a PMU measures voltage, current, etc. of its dedicated line and sends information to the corresponding PDC. In order not to overflow the distribution data center and provide it with level three abstraction, the PDC can only send information to it when an issue occurs or when the situation is critical. The reconfiguration orders from level one to level two and from level two to level three are the data transmission rates of a PDC and that of a PMU respectively.

Table 1 lists examples of the upward (cognitive information) and downward (reconfiguration orders) data flow sent in this context. 


\begin{tabular}{|c|c|c|}
\hline Levels & Cognitive Information $\Uparrow$ & Reconfiguration Orders $\Downarrow$ \\
\hline L1 - L2 & Aggregated data sensed by PMUs & Set data transmission rate \\
\hline L2 - L3 & Power on the line & Set data transmission rate \\
\hline
\end{tabular}

Table 1: Interaction between the distribution data center and a PMU

\subsubsection{Integration of renewable energy and storage facilities}

This section describes the L2 of Wind farm monitoring, PV farm monitoring and EV aggregator of figure 9. Renewable energy sources are difficult to handle because of the intermittent generation. The energy produced by a wind farm or a PV farm does not necessary coincide with the energy demand. The production of these renewable energy sources at time $t$ is sometimes much larger than the consumption at this same time, which can cause a large pressure on the grid. This is why a local control of a wind farm or a $\mathrm{PV}$ farm is required. Indeed, if a wind/PV farm exceeds a specific production threshold (sent by the distribution data center), a monitoring system of the wind/PV farm (L2) can send orders to one or several wind turbines/PV panels (L3) to switch OFF in order to reduce the total electricity generation.

Table 2 lists examples of cognitive information and reconfiguration orders sent in this context.

Electric vehicles (EV) can offer an efficient way of electricity storage. The possibility of offering ancillary services by using EV has already been proposed by means of using cars' batteries [7]. An aggregator such as a telecommunication operator (L2) receives information about the energy re- 


\begin{tabular}{|c|c|c|}
\hline Levels & Cognitive Information $\Uparrow$ & Reconfiguration Orders $\Downarrow$ \\
\hline L1 - L2 & $\begin{array}{c}\text { Total production of } \\
\text { wind/PV farm }\end{array}$ & $\begin{array}{c}\text { Set a production } \\
\text { threshold }\end{array}$ \\
\hline L2 - L3 & $\begin{array}{c}\text { Production of one wind } \\
\text { turbine/PV panel }\end{array}$ & $\begin{array}{c}\text { Switch OFF/ON } \\
\text { the wind turbine/PV panel }\end{array}$ \\
\hline
\end{tabular}

Table 2: Interaction from the distribution data center to a wind turbine/PV panel

quired to balance demand and production from the distribution data center. This aggregator then proposes, via a cellular network (cars are equipped with cellular antennas), to cars around, to sell their electricity at a certain price per minute/hour. The aggregator receives benefits from having distributed information and thus having contributed to ancillary services. It is important to notice that ancillary services are not in unique direction, i.e. cars can also extract energy if an overproduction is detected. This energy extraction is at lower price, so as to attract people to charge up their vehicles. Moreover, this EV aggregator entity acts as a charging station, i.e. it has the same role as a fuel pump.

Table 3 lists examples of cognitive information and reconfiguration orders sent in the EV aggregator context.

\subsubsection{Consumers participation (L2 Home Smart Meter of figure 8)}

The smart meter is essential to enable demand side management programs. In the coming years, a typical home will be equipped with about twenty-to-thirty smart electrical devices 24] that can interact with the smart 


\begin{tabular}{|c|c|c|}
\hline Levels & Cognitive Information $\Uparrow$ & Reconfiguration Orders $\Downarrow$ \\
\hline L1 - L2 & $\begin{array}{c}\text { Number of cars currently } \\
\text { (dis) charging (total energy } \\
\text { extracted and injected) }\end{array}$ & $\begin{array}{c}\text { Set energy required or } \\
\text { to be extracted in order to } \\
\text { balance supply and demand }\end{array}$ \\
\hline L2 - L3 & $\begin{array}{c}\text { Energy that the car is } \\
\text { currently supplying/extracting }\end{array}$ & $\begin{array}{c}\text { Set price proposition } \\
\text { for ancillary services } \\
\text { Set a location free/occupied }\end{array}$ \\
\hline
\end{tabular}

Table 3: Interaction from the distribution data center to cars batteries

meter. In addition to measuring consumption the smart meter will be able to operate devices. A centralized way to process the data and control the devices, i.e. all the data from all the devices sent to the distribution data center and processed by itself, seems difficult to imagine and implement practically, whereas a distributed vision would relieve the distribution data center. Since the smart meter is the link between a home and the distribution data center, this device is at level two in the HDCRAM deployment. In this distributed vision, the smart meter has the role of home energy manager, i.e. it has to manage all the smart electrical devices (level three) that consume, produce or store electricity and sensors that sense the environment.

Between level one and level two, reconfiguration orders can be load curtailments, in such cases where a customer has subscribed for a DLC (Direct Load Control) program or set electricity prices in the smart meter. In such instances, the customer may want to curtail its load or not. The cognitive information is the total energy consumption of the home. 
Level three is divided into five categories: the sheddable load, the adjustable load, devices that produce electricity, Devices that can store the electricity, sensors (of any kind).

Table 4 lists examples of cognitive information and reconfiguration orders between the level two smart meter and all the levels three related to this level two, as described above.

\begin{tabular}{|c|c|c|}
\hline Level $2-3$ & Cognitive Information $\Uparrow$ & Reconfiguration Orders $\Downarrow$ \\
\hline Sheddable & $\begin{array}{l}\text { Electricity consumption } \\
\text { Time at which the device } \\
\text { will start consuming }\end{array}$ & $\begin{array}{l}\text { Shift consumption to time } \\
t \text { (switch OFF until time } t \text { ) } \\
\text { Switch ON/OFF the device }\end{array}$ \\
\hline Adjustable & $\begin{array}{c}\text { Electricity consumption } \\
\text { Min power allowed at time } t \\
\text { Max power allowed at time } t\end{array}$ & $\begin{array}{c}\text { Switch the device } \\
\text { consumption to its minimum/ } \\
\text { maximum consumption }\end{array}$ \\
\hline Storage & $\begin{array}{l}\text { Batteries level of the car } \\
\text { Batteries state: charge, } \\
\text { discharged, etc. }\end{array}$ & $\begin{array}{l}\text { Change the batteries state: } \\
\text { charge, unplug from grid, etc. } \\
\text { Discharge in the grid. }\end{array}$ \\
\hline $\begin{array}{c}\text { Renewable } \\
\text { energy }\end{array}$ & $\begin{array}{l}\text { Production level } \\
\text { of the PV panels }\end{array}$ & $\begin{array}{l}\text { Switch OFF/ON } \\
\text { the PV panels }\end{array}$ \\
\hline $\begin{array}{l}\text { External } \\
\text { Sensors }\end{array}$ & $\begin{array}{l}\text { Send sensing data: } \\
\text { wind velocity, sunshine, } \\
\text { temperature, etc. }\end{array}$ & $\begin{array}{c}\text { Not really any } \\
\text { reconfiguration orders } \\
\text { but switch OFF/ON a sensor }\end{array}$ \\
\hline
\end{tabular}

Table 4: Interaction between level two smart meter and level three devices at home 
In the case where the customer is an industrial company, DSM can also be applied [25]. For example, the industrial Smart Meter can reduce power consumption of non-essential devices or switch on diesel generator during peak load hours. Thus, smart industrial management can be done in the same manner as smart home management.

More details on level 3 of consumer participation are given in the following section.

\subsection{Level 3 of consumer participation}

\subsubsection{The sheddable load}

The sheddable load can be reprogrammed at another time, i.e. can have its consumption shifted to off-peak hours. For instance, a washing machine can have its consumption shifted to night hours, where prices are lower.

\subsubsection{The adjustable load}

The adjustable load that cannot have its consumption totally shifted to later hours but can adapt its power level in order to decrease a bit the total electricity consumption of the house. An air-conditioner can decrease its electricity consumption by not decreasing too much the ambient temperature for example.

Paper [26] even proposes to divide the load into three categories which are sheddable, adjustable and load sensitive. The sensitive load refers to the load that cannot have its consumption shifted or adapted (or just very little adapted). But this category can be merged with the adjustable load by keeping in mind that there exists devices that have zero power level adaptation. 


\subsubsection{Electricity production}

The electricity generation produced by photovoltaic panels (PV) is provided in an intermittent way and depends on the environment. A local way to control those panels is desirable, i.e. switching ON/OFF the panels depending on the user requirements or distribution lines' states.

\subsubsection{Storage facilities}

With the advent of electric vehicles (EV), the possibility of storing energy at home has emerged. If the generation of the home PV panels is too large compared to the power consumption of all the other devices, the excessive energy will be injected into the grid, which is sometimes not desirable for the sake of the distribution network's performance. This energy could instead be stored in the user car's batteries in order to either use the car or use this stored energy when electricity prices are high.

\subsubsection{Sensors}

Sensors can be used to anticipate power consumption and production. They can be of many types irradiance sensors, wind sensors, temperature sensors, etc. For example, temperature sensors can inform the smart meter of the outside temperature. The smart meter will then decide at what time radiators must be switched $\mathrm{ON} / \mathrm{OFF}$, depending on the electricity price, grid pressure, thermal inertia of the building, etc. Wind sensors can also be useful: sensors sense the velocity of the wind, send this information to the smart meter which can decide to send it to the distribution data center and the latter can predict the electricity generation of a wind farm close to a specific location. 
All the devices listed above will have to communicate with the smart meter. Wireless communications is preferred as it is less intrusive and can be installed without any alteration work. But, if the number of devices is large and if some devices produce too many electromagnetic waves (such as a microwave), some frequency bands could be congested. A proposed solution is to use devices equipped with radio reconfigurable abilities and a decision making process such as OSA, so as to select the right band and channel that can be used by each device.

\section{A Multi-Agent Based Implementation of a Home Energy Man- ager}

This section presents a multi-agent based implementation of a home energy manager, which can be useful to simulate the behavior of a house with respect to electricity price changes. This implementation is based on the level two smart meter and the corresponding level three parts of the architecture presented in section 3: L3 manager of PV panels, washing machines, air conditioning, etc. The proposed implementation is restricted on these parts here, in order to have a quick simulation on a concrete case. The purpose of this simulation aims to show that the application of HDCRAM architecture provides benefits compared to the case where this architecture is not applied (without management).

\subsection{Java Agent DEvelopment Framework (JADE)}

In order to implement a home energy manager that includes independent entities that can communicate with each other, while maintaining a certain hierarchy (an entity cannot communicate with any other entities), 
the JADE platform was used [27].

JADE belongs to the agent-oriented programming (AOP) class, which is used to simulate artificial distributed systems. AOP is used to model an application as a set of autonomic, active and communicating entities called agents [28]. With these abilities, agents can independently make decisions and send any relevant information that they computed to other agents. Since JADE is used in the distributed system, agents can be easily added without any changes in the already implemented agents (they act independently).

\subsection{Simulations scenario}

A multi-agent based home energy manager is implemented. The concerned sub part of figure 8 and 9 in this scenario, is the level two home smart meter and the level three entities and operators below it. The thirteen electrical appliances considered in the scenario simulated can be classified in the four categories already mentionned :

- Sheddable load : dish washer, vacuum cleaner, oven, iron, washing machine and air dryer;

- Electricity production : PV agent

- Storage facilities : two electrical vehicle;

- Adjustable load : fridge, air conditioner, ventilator and radiator;

A simplified scheme of the architecture applied to the simulation scenario is depicted in Figure 10. 


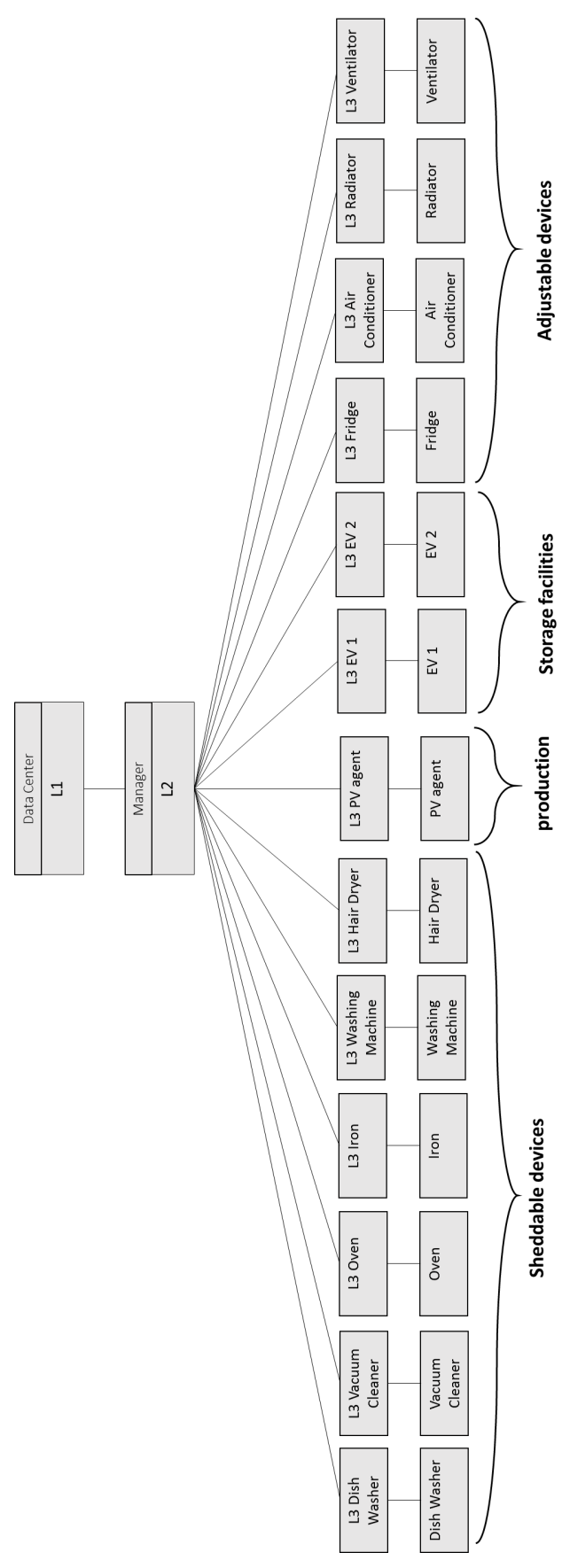

Figure 10: Simplified diagram of the architecture applied to the simulation scenario 
The aim of this simulation is to compare the instantaneous power consumed with and without the hierarchical manager. The implementation is time-dependent and models a whole day divided in 24 periods (time step = one hour, this could be changed depending on the required precision without loss of generality). At each hour $h$, in order to reduce the pressure on the power grid, the aim of the manager is to minimize the magnitude of the total power consumption $\left|P_{\text {tot }}(h)\right|$.

The expression of the total power consumption $P_{t o t}(h)$ may be decomposed into the sum of the power consumption of each device.

For each hour, the total power consumption can be written:

$$
P_{\text {tot }}(h)=P_{\text {cons }}(h)-P_{\text {prod }}(h) .
$$

The expression of the total power consumed at hour $h, P_{\text {cons }}(h)$, is :

$$
P_{\text {cons }}(h)=\sum_{i=1}^{N_{a}} P_{a d j}^{i}(h)+\sum_{i}^{N_{s}} P_{\text {shed }}^{i}(h)+P_{s t}(h),
$$

where $N_{a}$ and $N_{s}$ denote respectively the number of adjustable and sheddable devices, $P_{a d j}^{i}(h)$ the power consumption of one of the adjustable devices during hour $h, P_{\text {she }}^{i}(h)$ the power consumption of one of the sheddable devices during hour $h$ and $P_{s t}(h)$ is the power stored into the batteries of the two electrical vehicles. This power is produced by PV panels and stored because it isn't instantaneously consumed.

The total power produced $P_{\text {prod }}(h)$ :

$$
P_{\text {prod }}(h)=P_{P V}(h)+P_{\text {del }}(h),
$$


where $P_{P V}(h)$ is the power produced by $\mathrm{PV}$ panels and $P_{d e l}(h)$ is the power delivered by the batteries of the two electrical vehicles where PV current is stored when it is not consumed.

Finally, if we denote $\Delta S(h)=P_{s t}(h)-P_{\text {del }}(h)$ the power variation induced by the batteries, the total power consumption becomes :

$$
P_{\text {tot }}(h)=\sum_{i=1}^{N_{a}} P_{a d j}^{i}(h)+\sum_{i=1}^{N_{s}} P_{\text {shed }}^{i}(h)-P_{P V}(h)+\Delta S(h) .
$$

It is important to note that, each of the four terms of this sum relates to one level 3 unit of the architecture.

In our scenario, each of the two electrical vehicles can store $15 \mathrm{kWh}$ and the power delivered or stored by each of them is between -3000 and $3000 \mathrm{~W}$.

The power produced by PV panels depends on the weather, for simulation we consider that at each hour the power produced $P_{P V}(h)$ is uniformly distributed between $0 \mathrm{~W}$ and a maximum value which depends on the time, $P_{P V}(h) \sim \mathcal{U}\left(0, M_{P V}(h)\right)$. The values of $M_{P V}(h)$ are referenced in Table 5 .

\begin{tabular}{|c|c|}
\hline Hours of the day $[\mathrm{h}]$ & maximum Power generated $[\mathrm{W}]$ \\
\hline$h \in[21 ; 4]$ & 30 \\
\hline$h \in[5 ; 7] \cup[18 ; 20]$ & 4000 \\
\hline$h \in[8 ; 17]$ & 12000 \\
\hline
\end{tabular}

Table 5: $P V$ agent used for the simulation 
Each of the $N_{a}=4$ adjustable devices are listed in Table 6. When the total power consumption is high, the power consumed by those devices is reduced from their nominal power consumption to their minimal power consumption. The six sheddable devices are listed in Table 7, they must be used for an hour between their earliest and latest time of consumption during the day.

\begin{tabular}{|c|c|c|}
\hline Agent's name & $\begin{array}{c}\text { Minimum power level } \\
{[\mathrm{W}]}\end{array}$ & $\begin{array}{c}\text { Nominal power level } \\
{[\mathrm{W}]}\end{array}$ \\
\hline AirConditioner & 2000 & 3000 \\
\hline Radiator & 500 & 1000 \\
\hline Fridge & 100 & 300 \\
\hline Ventilator & 30 & 50 \\
\hline
\end{tabular}

Table 6: Adjustable devices agents used for the simulation

Each hour, all L3_CRMu in charge of power production, storage and adjustable devices send cognitive information to the L2_CRMu (respectively the power produced, state of batteries and adjustable load requirements). This entity computes the power consumption of the hour and then sends configuration order (adjustable devices to start, power level of sheddable devices and power to deliver or store for batteries) to the L2_ReMu which transmits it to the corresponding L3_ReMus. Configuration orders must take into account the constraint of the devices pre-set in the manager. Figure 11 shows communication paths between the L2 manager and the L3 units empoyed for simulations.

Note that HDCRAM is able to support that some devices in white have 


\begin{tabular}{|c|c|c|c|}
\hline Agent's name & $\begin{array}{c}\text { Consumption } \\
\text { when ON }[\mathrm{W}]\end{array}$ & $\begin{array}{c}\text { Earliest time of } \\
\text { consumption }[\mathrm{h}]\end{array}$ & $\begin{array}{c}\text { Latest time of } \\
\text { consumption }[\mathrm{h}]\end{array}$ \\
\hline WashingMachine & 1690 & 0 & 23 \\
\hline Dryer & 2400 & 0 & 9 \\
\hline Oven & 3105 & 17 & 20 \\
\hline VacuumCleaner & 1874 & 9 & 12 \\
\hline Iron & 1960 & 10 & 14 \\
\hline DishWasher & 1060 & 21 & 23 \\
\hline HairDryer & 1733 & 17 & 22 \\
\hline
\end{tabular}

Table 7: Sheddable devices agents used for the simulation

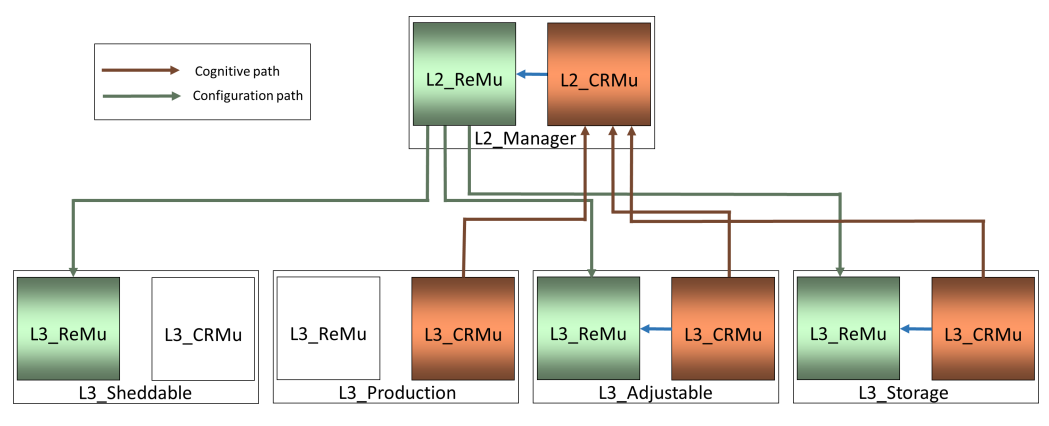

Figure 11: Communication paths between L3 and the L2 manager 
no role in the scenario, either because they have no capability to sense and to be swithed remotely, or just because they have not been considered in the scenario. HDCRAM infrastructure is deployed where it is only necessary, depending on the use cases that should be supported by the management system.

\subsection{Simulations results}

Figure 12 shows the comparison between a classical utilization of the operators and the result of the HDCRAM implementation presented above for a period of 24 hours.

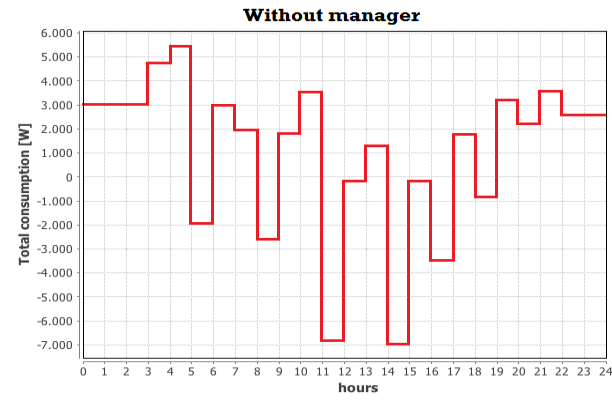

(a) Classical

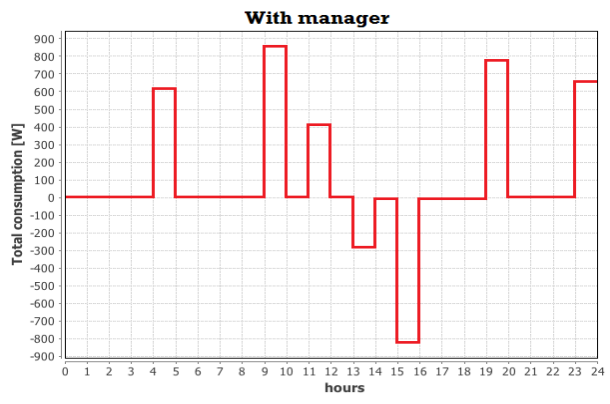

(b) HDCRAM

Figure 12: Simulation results of the power consumption in $\mathrm{W}$ in function of time, as described in section 4.3 (a) when a classical utilization of the electrical devices is done and (b) when HDCRAM is used as a management facility of the home power consumption

In a classical utilization of the same electrical devices (manual mode), in Figure 12 a), there is no consideration to the current load, and storage facilities are not considered. The adjustable devices operate at one power 
level during the day (between $6 \mathrm{AM}$ and $7 \mathrm{PM}$ ) and at another during the night (a customer does not often change the power level of its devices to reduce the consumption). The sheddable devices consume electricity at a random hour in their hour bounds (hour constraints).

Thanks to the proposed power management, the power consumption is zero $\left(P_{t o t}(h)=0\right)$ for 17 of the 24 hours of the day and the peak consumption is strongly reduced (figure 12. This gain is due to the management of storage facilities, sheddable and adjustable load:

- Batteries allow a better distribution of the produced energy, power provided by solar panels is stored during the day and used at night. This part of the management doesn't reduce the quality of service but is limited by the batteries size.

- The use of sheddable devices is better distributed over the day, this reduces significantly the peak production. Moreover, the constraint on hours of use (earliest and latest hour) limits inconvenience for the consumer.

- Reducing power consumption of adjustable devices reduces the quality of service. Consequently, the manager should use this possibility wisely. At each hour, the impact of power reduction is limited by the total adjustable load (1720 W in the scenario simulated).

Table 8 compares the results obtained in automatic and manual mode. It is clear that the variability and the maximum/minimum power levels in manual mode are much greater than in automatic mode. 


\begin{tabular}{|c|c|c|}
\hline Mode & $\begin{array}{c}\text { Peak } \\
\text { consumption } \\
{[W]}\end{array}$ & $\begin{array}{c}\text { Peak } \\
\text { generation } \\
{[W]}\end{array}$ \\
\hline HDCRAM & 850 & 800 \\
Classical & 5500 & 7000 \\
\hline
\end{tabular}

Table 8: Comparison between HDCRAM and a classical utilization

Therefore, with the HDCRAM implementation, the customer will have a lower electricity bill (much less energy drawn from the grid) and the distribution network will have less pressure on its grid (much less energy injected to the grid and much less variation).

\section{Conclusion}

HDCRAM is proposed as an efficient tool to model and represent the communication interactions in the Smart Grid. Moreover, this tool could be used to distribute the tasks amongst the components of the SG, and HDCRAM will link all of them together. HDCRAM can help specifying the entire management system and its framework can help with generating the simulation code first, then the implementation code. The simulation results are very promising. In future work, retailers will be include in the architecture and communication access and protocol will be studied.

\section{Acknowledgment}

Part of this work is supported by the project SOGREEN (Smart pOwer Grid for Energy Efficient small cell Networks), which is funded by the French 
national research agency, under the grant agreement coded: N ANR-14CE28-0025-02 and by Région Bretagne, France.

\section{References}

[1] E. Commission, "European Technology Platform SmartGrids Vision and Strategy for Europes Electricity Networks of the Future," 2006.

[2] E. C. T. F. for Smart Grids, "Expert Group 1: Functionalities of Smart Grids and Smart Meters: Final Deliverable," December 2010.

[3] 110th United States Congress, "Energy Independence and Security Act of 2007," January 2007.

[4] D. of Energy of USA, "Communications Requirements of Smart Grid Technologies," tech. rep., October 2010.

[5] J. Mitola and J. Maguire, G.Q., "Cognitive radio: making software radios more personal," Personal Communications, IEEE, vol. 6, pp. 1318, Aug 1999.

[6] S. Haykin, "Cognitive radio: brain-empowered wireless communications," Selected Areas in Communications, IEEE Journal on, vol. 23, pp. 201-220, Feb 2005.

[7] E. Hossain, Z. Han, and H. Poor, Smart Grid Communications and Networking. Smart Grid Communications and Networking, Cambridge University Press, 2012.

[8] A. Khan, M. Rehmani, and M. Reisslein, "Cognitive radio for smart grids: Survey of architectures, spectrum sensing mechanisms, and net- 
working protocols," Communications Surveys Tutorials, IEEE, vol. PP, no. 99, pp. 1-1, 2015.

[9] R. Qiu, Z. Hu, Z. Chen, N. Guo, R. Ranganathan, S. Hou, and G. Zheng, "Cognitive radio network for the smart grid: Experimental system architecture, control algorithms, security, and microgrid testbed," Smart Grid, IEEE Transactions on, vol. 2, pp. 724-740, Dec 2011.

[10] Y. Zhang, R. Yu, M. Nekovee, Y. Liu, S. Xie, and S. Gjessing, "Cognitive machine-to-machine communications: visions and potentials for the smart grid," Network, IEEE, vol. 26, pp. 6-13, May 2012.

[11] R. Yu, Y. Zhang, S. Gjessing, C. Yuen, S. Xie, and M. Guizani, "Cognitive radio based hierarchical communications infrastructure for smart grid," Network, IEEE, vol. 25, pp. 6-14, September 2011.

[12] G. Shah, V. Gungor, and O. Akan, "A cross-layer qos-aware communication framework in cognitive radio sensor networks for smart grid applications," Industrial Informatics, IEEE Transactions on, vol. 9, pp. 1477-1485, Aug 2013.

[13] L. Godard, C. Moy, and J. Palicot, "From a configuration management to a cognitive radio management of sdr systems," in Cognitive Radio Oriented Wireless Networks and Communications, 2006. 1st International Conference on, pp. 1-5, June 2006.

[14] O. Lazrak, S. Bourbia, C. Moy, D. L. Guennec, P. Leray, K. Grati, and A. Gazel, "Management architecture for green cognitive radio equip- 
ments," Transactions on Emerging Telecommunications Technologies, vol. 24 , no. 7-8, pp. 683-691, 2013.

[15] O. Lazrak, C. Moy, and P. Leray, "Modeling Cognitive Radio Equipments for Opportunistic Spectrum Access," in Wireless Innovation Forum European Conference on Communications Technologies and Software Defined Radio 2013, (Munich, Germany), June 2013.

[16] R. Verschae, H. Kawashima, T. Kato, and T. Matsuyama, "A distributed hierarchical architecture for community-based power balancing," in Smart Grid Communications (SmartGridComm), 2014 IEEE International Conference on, pp. 163-169, Nov 2014.

[17] D. Li and S. Jayaweera, "Distributed smart-home decision-making in a hierarchical interactive smart grid architecture," Parallel and Distributed Systems, IEEE Transactions on, vol. 26, pp. 75-84, Jan 2015.

[18] C. xia Dou and B. Liu, "Multi-agent based hierarchical hybrid control for smart microgrid," Smart Grid, IEEE Transactions on, vol. 4, pp. 771-778, June 2013.

[19] L. Godard, C. Moy, and J. Palicot, "An executable meta-model of a hierarchical and distributed architecture management for cognitive radio equipments," annals of telecommunications - annales des télécommunications, vol. 64, no. 7-8, pp. 463-482, 2009.

[20] C. Moy, "High-level design approach for the specification of cognitive radio equipments management apis," Journal of Network and Systems Management, vol. 18, no. 1, pp. 64-96, 2010. 
[21] J. Palicot, Radio Engineering: From Software Radio to Cognitive Radio. Wiley-ISTE, Aug. 2011.

[22] K. Moslehi and R. Kumar, "A reliability perspective of the smart grid," Smart Grid, IEEE Transactions on, vol. 1, pp. 57-64, June 2010.

[23] D. Tholomier, H. Kang, and B. Cvorovic, "Phasor measurement units: Functionality and applications," in Power Systems Conference, 2009. PSC '09., pp. 1-12, March 2009.

[24] Z. Fan, G. Kalogridis, C. Efthymiou, M. Sooriyabandara, M. Serizawa, and J. McGeehan, "The new frontier of communications research: Smart grid and smart metering," in Proceedings of the 1st International Conference on Energy-Efficient Computing and Networking, e-Energy '10, (New York, NY, USA), pp. 115-118, ACM, 2010.

[25] E. Hamid, P. Nallagownden, N. Mohd Nor, and M. Muthuvalu, "Intelligent demand side management technique for industrial consumer," in Intelligent and Advanced Systems (ICIAS), 2014 5th International Conference on, pp. 1-6, June 2014.

[26] R. H. Khan and J. Y. Khan, "Review article: A comprehensive review of the application characteristics and traffic requirements of a smart grid communications network," Comput. Netw., vol. 57, pp. 825-845, Feb. 2013.

[27] A. Garcia, J. Oliver, and D. Gosch, "An intelligent agent-based distributed architecture for smart-grid integrated network management," in Local Computer Networks (LCN), 2010 IEEE 35th Conference on, pp. 1013-1018, Oct 2010. 
[28] F. Bellifemine, G. Caire, and D. Greenwood, Developing Multi-Agent Systems with JADE. Wiley Series in Agent Technology, Wiley, 2007. 